\title{
Continental variation in wing pigmentation in Calopteryx damselflies is related to the presence of heterospecifics
}

Wing pigmentation in Calopteryx damselflies, caused by the deposition of melanin, is energetically expensive to produce and enhances predation risk. However, patterns of melanisation are used in species identification, greater pigmentation is an accurate signal of male immune function in at least some species, and there may be a role for pigment in thermoregulation. This study tested two potential hypotheses to explain the presence of, and variation in, this pigmentation based on these three potential benefits using 907 male specimens of Calopteryx maculata collected from 49 sites (34 discrete populations) across the geographical range of the species in North America: (i) pigmentation varies with the presence of the closely related species, Calopteryx aequabilis, and (ii) pigment increases at higher latitudes as would be expected if it enhances thermoregulatory capacity. No gradual latitudinal pattern was observed, as might be expected if pigmentation was involved in thermoregulation. However, strong variation was observed between populations that were sympatric or allopatric with $C$. aequabilis. This variation was characterised by dark wings through allopatry in the south of the range and then a step change to much lighter wings at the southern border of sympatry. Pigmentation then increased further north into the sympatric zone, finally returning to allopatry levels at the northern range margin. These patterns are qualitatively similar to variation in pigmentation in $C$. aequabilis, meaning that the data are consistent with what would be expected from convergent character displacement. Overall, the results corroborate recent research that has suggested sexual selection as a primary driver behind the evolution of wing pigmentation in this group. 
3 Author: Christopher Hassall*

4 Affiliation: School of Biology, University of Leeds

5 Location: Leeds, UK

$6 *$ Corresponding author

7 Address: School of Biology, University of Leeds, Woodhouse Lane, Leeds, LS2 9JT, UK

8 Telephone: +4401133435578

$9 \quad$ Email: c.hassall@leeds.ac.uk 
10 ABSTRACT

11 Wing pigmentation in Calopteryx damselflies, caused by the deposition of melanin, is

12 energetically expensive to produce and enhances predation risk. However, patterns of

13 melanisation are used in species identification, greater pigmentation is an accurate signal of male

14 immune function in at least some species, and there may be a role for pigment in

15 thermoregulation. This study tested two potential hypotheses to explain variation in this

16 pigmentation using 907 male specimens of Calopteryx maculata collected from 49 sites (34

17 discrete populations) across the geographical range of the species in North America: (i)

18 pigmentation varies with the presence of the closely related species, Calopteryx aequabilis, and

19 (ii) pigment increases at higher latitudes as would be expected if it enhances thermoregulatory capacity. No gradual latitudinal pattern was observed, as might be expected if pigmentation was involved in thermoregulation. However, strong variation was observed between populations that were sympatric or allopatric with $C$. aequabilis. This variation was characterised by dark wings through allopatry in the south of the range and then a step change to much lighter wings at the southern border of sympatry. Pigmentation then increased further north into the sympatric zone, finally returning to allopatry levels at the northern range margin. These patterns are qualitatively similar to variation in pigmentation in C. aequabilis, meaning that the data are consistent with what would be expected from convergent character displacement. Overall, the results corroborate recent research that has suggested sexual selection as a primary driver behind the evolution of wing pigmentation in this group.

30 Keywords: dragonfly; Odonata; melanin; North America; species recognition; allopatry; wing;

31 sympatry; thermoregulation 


\section{INTRODUCTION}

The pigment melanin plays a key role in both colouration of the insect integument and in defence against pathogens. In vertebrates, there is evidence for a cost of carotenoid - but not melanin based pigmentation (Badyaev \& Young 2004; McGraw \& Hill 2000). However, condition dependence of invertebrate melanin-based colouration indicates an energetic cost in this group (Hooper et al. 1999; Talloen et al. 2004), suggesting that there may be a strong effect of taxon on the costs of melanin production (Stoehr 2006). In addition to biochemical synthesis the presence of additional melanin in the cuticle may result in a cost due to increased predation risk due to higher conspicuousness (Svensson \& Friberg 2007).

Pigmentation has also been linked with thermoregulation. For example, Colias butterflies living at higher altitudes possess darker wings which enable greater absorption of solar energy (Watt 1968) and thermoregulation has been proposed as a selective pressure which drove the early evolution of insect wings ( holds its wings close to the ground in such a way as to create a pocket of warm air close to its body, as well as undergoing temperature-mediated physiological colour change (Sternberg 1996, 1997). There has been some suggestion that the body colouration of coenagrionid damselflies reflects the limits of their thermal tolerance (Hilfert-Rüppell 1998). Some equivocal evidence exists for a negative relationship between temperature and the degree of wing pigmentation at a population level in Calopteryx damselflies (Outomuro \& Ocharan 2011), while broader comparative analyses of the Calopterygidae show a strong association of pigmentation with species at higher latitudes (Svensson \& Waller 2013). An interspecific comparison of C. virgo (darkly-pigmented) and C. splendens (less-pigmented) showed that C. virgo emerged earlier in the year and maintained a higher body temperature at lower ambient temperatures ( $\underline{\text { Svensson } \&}$ Waller 2013). Thus individuals inhabiting cooler regions or emerging during cooler parts of the flight period may benefit from possessing melanin to assist with the absorption of solar radiation to aid thermoregulation, resulting in a positive correlation between pigmentation and latitude (or a negative correlation with temperature). However, field studies suggest that pigmented wings are frequently cooler than the body temperature, suggesting that no heat transfer is occurring (Tsubaki et al. 2010). 
damselfly genus Calopteryx, one pair in Europe and one pair in North America, have received particular attention with respect to interspecific interactions. C. virgo and C. splendens overlap greatly in their distributions in Europe, with $C$. virgo extending slightly further south into the Iberian peninsula and north into Scandinavia, while C. splendens is more common in eastern Europe (Dijkstra \& Lewington 2006). Reciprocal hybridisation has been documented in this pair (Tynkkynen et al. 2008) and species isolation is based on both male and female mate discrimination on wing pigmentation (Svensson et al. 2007). Interactions between males of the two species tend to be dominated by $C$. virgo, and there is evidence that these interspecific interactions may result from poor species recognition in $C$. virgo which mistake large-spotted $C$. splendens for conspecifics (Tynkkynen et al. 2004). A decline in the size of the C. splendens wing spot was found in association with greater C. virgo density (Tynkkynen et al. 2004) and where the two species were sympatric (Honkavaara et al. 2011). Thus this species pair may exhibit agonistic character displacement (Grether et al. 2009). This selection for smaller wing spot size in territorial encounters may be traded-off against a selection for larger wing spot size by female mate choice in C. splendens ( $\underline{\text { Siva-Jothy 1999). }}$.

C. maculata (Beauvois) and C. aequabilis (Say) overlap to a lesser extent in North America. C. maculata is found in the south east of the continent while C. aequabilis occupies a band stretching east-west across the northern part of the continent. There is currently no evidence of hybridisation between C. maculata and C. aequabilis (Mullen \& Andrés 2007), despite the readiness of $C$. maculata males to form tandems with $C$. aequabilis females (Waage 1975). This readiness decreases as $C$. aequabilis female wing pigmentation decreases, rendering it less similar to the C. maculata female (Waage 1975). C. aequabilis exhibits considerable variation in the size of the pigmented area of the hind wing in males while female hind and fore wings become lighter in populations that are sympatric with C. maculata (Waage 1979). Thus this species pair may exhibit reproductive character displacement (Waage 1979).

Previous studies on patterns of pigmentation in Calopteryx damselflies have focused on its role in specific processes such as antagonistic interactions, sexual signalling and immunology. Studies of geographical variation in pigmentation have been conducted, but these were restricted to the small proportion of the range in the southern UK for Calopteryx splendens/virgo (10 populations, $\underline{\text { Honkavaara et al. 2011) and the northeast corner of the range of C. maculata/aequabilis (26 }}$ populations, Waage 1979). The broadest study of Calopteryx maculata/aequabilis was still 
94 focused on the zone of sympatry between the two species, with few populations sampled far

95 beyond that zone (15 populations, Mullen \& Andrés 2007). This study provides a

96 comprehensive description of variation in pigmentation which permits the comparison of competing hypotheses at a continental scale using 907 C. maculata males from 34 sites across the entire range. With these data, two potential hypotheses for geographical variation in the wing pigmentation of $C$. maculata males are tested: (i) pigmentation is positively related to latitude (or negatively related to temperature) as predicted by a thermoregulatory mechanism, and (ii) pigmentation varies with range overlap with $C$. aequabilis as would be expected from character displacement. Under the first hypothesis, it would be expected that wing pigmentation would increase with latitude such that individuals experiencing colder average temperatures exhibited more heat-absorbing pigment in their wings. Under the second hypothesis, we would expect a discontinuity in the latitudinal pattern at the edge of the zone of sympatry. Given the generally dark colour of $C$. maculata wings, this shift might take the form of a lightening of $C$. maculata wings to provide greater difference compared to the black wing tip of $C$. aequabilis.

\section{METHODS}

A total of 907 male specimens of $C$. maculata were collected from 49 sites across the entire range of $C$. maculata. Of these 49 sites, a number of samples were consolidated where sites were $<4 \mathrm{~km}$ apart (the maximum dispersal distance recorded for a Calopteryx species, by the congener $C$. virgo Stettmer 1996) and, hence, not independent, to give 34 samples (Figure 1, for details, see Table S1). Collections took place between 13 May and 7 August 2010 and mean sample size from each site was $26.7 \pm 2.9$ (SE). Information on the body size of these specimens can be seen in a previous paper (Hassall 2013). Specimens were taken from stream sites where almost all individuals are reproductively mature adults (note, however, that very occasional younger individuals occupying stream sites may have less-pigmented wings which could add noise to the data, Kirkton \& Schultz 2001). Wings were dissected from the body as close to the thorax as possible and the right hind leg was removed. The four wings were mounted on transparent, adhesive tape (Scotch Matte Finish Magic Tape). Wings were scanned using the slide scanner on an Epson V500 PHOTO flatbed scanner with fixed exposure at 1200dpi. The slide scanner contains a light source on the opposite side of the object to the scanner and, hence, measures transparency rather than reflectance. 
124 Due to differences between individuals in the area of wing obscured by the thorax and the 125 accuracy of dissections, all wing images were modified to omit the arculus and all regions before 126 the first cross-veins. Wing pigmentation was measured as the average grayscale value of the 127 wing. Grayscale varies between 0 (black) and 255 (white), hence greater values correspond to 128 lighter, more transparent wings. This value was calculated for each pixel on the image, with an 129 average of 503,647 pixels $( \pm 1202$ SE) on the fore wing and 496,122 pixels $( \pm 1260)$ on the hind 130 wing. All measurements were carried out in ImageJ (Rasband 1997-2007). During 131 measurements, any damage to wings was noted and those measurements which could not be 132 accurately quantified were excluded. This resulted in the exclusion of 140 fore wing and 116 133 hind wing pigmentation measurements (see Table S1 for sample sizes).

134 Mean monthly temperature was extracted for each of the 34 sampling sites in ArcGIS (v9.2) 135 (ESRI 2006) using the WORLDCLIM gridded "current conditions" dataset (Haylock et al. 2008). 136 The spatial resolution was 10 arc-minutes and only data for the months in which specimens were 137 collected at each site (May, June, July or August) were used. Sympatry was determined using 138 distributional records from Odonata Central (Abbott 2007) (Figure 1). A sample from Ohio 139 which is the most-southern population in the sympatric zone may not be sympatric with $C$. 140 aequabilis at a local level despite lying within the area bounded by populations of C. aequabilis. 141 However, the population is included as sympatric for the analysis. Ordinal date (days since 1st 142 Jan) was used to measure time of season, with which pigmentation has been shown to vary in 143 Calopteryx dimidiata (Burmeister) (Johnson 1973).

144 Response variables, predictors and model residuals were tested for normality using Shapiro-Wilk 145 tests. Transformations were applied where those assumptions were not met. General linear 146 models weighted by the square root of the sample size were constructed in R ( $\underline{\mathrm{R} \text { Development }}$ 147 Core Team 2013) with fore wing and hind wing pigmentation as response variables. It is unclear 148 (i) how atmospheric temperature relates to the temperature experienced by aquatic larvae and (ii) 149 what aspect of temperature variation might influence odonate pigmentation. As a result, latitude 150 was used as a general proxy for temperature variation. Furthermore, after transformation for 151 normality, latitude and annual temperature were very highly correlated $(\mathrm{r}=0.860, \mathrm{p}<0.001)$. 152 Latitude, ordinal date on which specimens were collected, and sympatry with C. aequabilis were 153 included as predictors in the GLMs. An interaction between latitude and sympatry was also 154 included to evaluate the effect of range overlap on latitudinal trends. Where specimens were 
collected across multiple dates, the average of those dates was taken for the sample. Subsets of data corresponding to different regions of the range (i.e. whole range, allopatric range and sympatric range) were analysed using Pearson correlations to investigate whether latitudepigmentation patterns varied. Similarity between specimens from different geographical locations may be as much a function of their proximity as of any underlying patterns. This should be corrected for using spatial autoregressive models, but only if the residuals of the uncorrected models are spatially autocorrelated (Diniz-Filho et al. 2003). The residuals of all models were tested for spatial autocorrelation using SAM v3.0 (Rangel et al. 2010).

Supplementary data on the degree of wing pigmentation in C. maculata females and $C$. aequabilis females are available from a previous study and provide a useful comparison (Waage 1979). Mean transparency of the dark regions of female C. maculata and C. aequabilis wings, and the proportion of the wing that was pigmented in C. aequabilis males were extracted from Waage (1979), see Figure 3B-D. Data extraction was carried out using the GetData Graph Digitizer v2.24 (Fedorov 2008). Waage used a densitometer to quantify relative transparency between samples and so his absolute measurements are not directly comparable to the present study. However, the data still permit a qualitatively comparison of variation between the species. All data for the C. maculata males used in this study are available as electronic supplementary information (Table S1 for site summaries, Table S2 for individual measurements).

\section{RESULTS}

Note that throughout the results, wing transparency is used as the measure of colouration and this is inversely related to the degree of pigmentation in the wing. A guide is shown in Figure 2 to give examples of varying degrees of wing transparency. When individual data were averaged across sites there was a highly significant correlation between hind and fore wing pigmentation $(\mathrm{n}=34, \mathrm{r}=0.985, \mathrm{p}<0.001)$ and so only fore wing data are shown in Figures 1, 2 and 3A. The results from GLMs demonstrate that sympatry with C. aequabilis and latitude influenced variation in fore and hind wing pigmentation but that the effect of latitude was dependent upon sympatry (Table 1). Residuals of these models were not spatially autocorrelated as revealed by SAM and so no control for spatial autocorrelation was necessary. In the allopatric zone, male $C$. maculata showed consistently dark wings (Figures 1 and 2). The exception was a single population in Texas in which individuals had lighter wings. Where the range of $C$. aequabilis overlaps the range of C. maculata, wings suddenly become lighter and then darken further north 
in the sympatric zone. There is a significant correlation between latitude and mean population pigmentation for populations of $C$. maculata when sympatric with $C$. aequabilis $(\mathrm{n}=21, \mathrm{r}=-0.743$, $\mathrm{p}<0.001$ - note that this negative correlation means increasing pigmentation with latitude) but not for allopatric populations $(\mathrm{n}=13, \mathrm{r}=-0.280, \mathrm{p}=0.332)$ or populations as a whole $(\mathrm{n}=34, \mathrm{r}=0.150$, $\mathrm{p}=0.397)$. The decline in pigmentation does not appear to result from a continuation of any trends from the allopatric region but occurs suddenly.

The relative wing pigmentation between geographical locations that has previously been reported for C. maculata females, C. aequabilis females, and C. aequabilis males (Waage 1979) appears to follow the same geographic pattern as that found in the present study for C. maculata males (Figure 3). In allopatry, wings tend to be more pigmented (lower transparency). At the southern margin of the sympatric zone wings tend to be less pigmented (higher transparency) and pigmentation increases towards the northern margin of the sympatric zone in all four groups. Note that only qualitative comparisons are possible between the groups due to variation in the methods used to obtain the data, but that these comparisons suggest a consistent pattern.

\section{DISCUSSION}

I demonstrate that, contrary to previous assumptions, males of C. maculata vary greatly in their pigmentation and this variation coincides with the presence of a congener, C. aequabilis. Qualitatively similar patterns of pigmentation have been observed in females of the same species and in females of the heterospecific $C$. aequabilis. Across the entire range, no gradual latitudinal patterns are present in wing pigmentation which would be expected if a covariate of latitude (be it temperature or another variable) was influencing pigmentation. However, within the zone of sympatry with $C$. aequabilis, wings become progressively darker as latitude increases. This finding not only provides another important component of a well-studied evolutionary system (the C. maculata/aequabilis species pair) but also constitutes a thorough test of intraspecific variation in pigmentation with changing latitude at a continental scale.

211 It has previously been stated that Calopteryx maculata "...has dark wings and shows little 212 geographic variation in the wing pattern" (Mullen \& Andrés 2007) and that a "...sympatric shift in 213 wing pigmentation was exhibited by females of [C. maculata and C. aequabilis] but only by 214 males in C. aequabilis" (Honkavaara et al. 2011). This originated in a misinterpretation of the 215 work of Waage (1979) who focused only female pigmentation in C. maculata and did not 
measure that in males, stating that "extent of the dark area in C. maculata males was not measured as their wings are 95-100\% pigmented" and "...wings of $C$. maculata are entirely dark and vary only in size... among the populations sampled" (Waage 1979, p106 and 108, respectively) but did not measure the intensity of pigmentation. However, from a broader comparison of sites, the degree of variation is marked (see the comparison of wing pigmentation levels in Figure 2) and varies depending on sympatry or allopatry with C. aequabilis. No evidence exists for latitudinal patterns in pigmentation apart from a latitudinal decline in pigmentation through the sympatric zone.

From a previous study it has been shown that $C$. aequabilis reduces its pigmentation progressively in populations that are located deeper inside the range of C. maculata (wing pigmentation is significantly correlated with latitude, see Table 1 in Waage 1979) and it has been assumed that this was to enhance species recognition where dark-winged C. maculata were present. However, it appears that the northward increase in pigmentation within the sympatric zone is also present in C. maculata, with qualitatively similar trends in increasing pigmentation further north in both sexes of both $C$. maculata and $C$. aequabilis. This pattern is consistent with

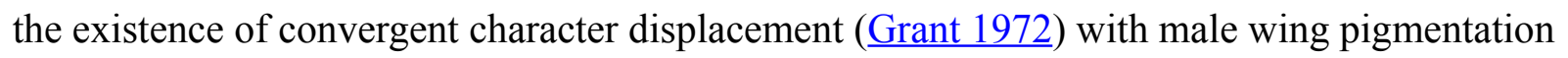
changing to match variations in female $C$. aequabilis pigmentation intensity and male $C$. aequabilis wing spot size (see Figure 3 for a comparison with Waage's (1979) data). However, a notable difference between the two trends is that the decline in pigmentation in C. maculata males is found in both wings, while this is only true for the hind wing in C. aequabilis (Waage 1979). This difference may relate to variations between species in the "cross-displays" performed by males to court females, which result in the more prominent display of hind wings in $C$. aequabilis (Waage 1973).

It is important to note that the previous demonstration of character displacement involved behavioural differences between species. The key observation was that C. maculata males exhibit a greater ability to discriminate between conspecific and heterospecific females when in sympatry than when in allopatry (Waage 1975). This can be taken as evidence of a cost of confused mating by $C$. maculata which leads to a selective pressure acting on the reinforcement of species identification. The present study provides a description of apparent convergence in a character that is key to discriminating between species, which appears to render both sexes of both species less discriminable. This observation runs counter to what would be expected given 
247 this selection pressure. Furthermore, the pattern cannot be explained by correlations with latitude

248 or temperature, which might be predicted based on the fact that melanin can play a role in

249 thermoregulation at higher latitudes (leading to a positive correlation between latitude and

250 pigmentation), as the levels of pigmentation return to allopatric levels (dark pigmentation) at the

251 northern-most sites (Figures 1, 2 and 3).

252 The pattern of results effectively appear to rule out temperature and latitude as causal factors in

253 the broader trend, although these have been suggested to influence geographic variation in

254 odonate colour (Hilfert-Rüppell 1998) and are strongly associated with the occurrence of wing

255 pigmentation across the Calopterygidae as a group ( $\underline{\text { Svensson \& Waller 2013 }}$ ). It is worth noting

256 that this is a purely correlative study, albeit involving intensive sampling of populations across an

257 extensive geographical area. The relatively constant levels of wing transparency through the

258 allopatric zone offer no evidence of a latitudinal or temperature-driven cline in pigmentation,

259 although the results are consistent with such a cline (showing declining transparency further

260 north) within the zone of sympatry. Stream temperatures measured in situ would provide a far

261 closer approximation of the thermal environment within which the animals develop, and there is

262 the potential that Calopteryx sp. may specifically select water bodies with particular thermal

263 regimes (as they do for a large number of other parameters, Siva-Jothy et al. 1995). Hence, while

264 latitude and temperature are strongly correlated, small (e.g. catchment) scale variations in water

265 temperature may still be operating. Calopteryx can be maintained in laboratory conditions and so

266 a common garden experiment that examined the impacts of varying temperature on larvae from

267 multiple populations would provide a thorough and robust test of these competing hypotheses.

268 Another mechanism that has been implicated in driving changes in odonate colour is the

269 avoidance of harassment by conspecifics (Van Gossum et al. 2001) or heterospecifics (Tynkkynen

270 et al. 2004). Evidence for this playing a role in calopterygid damselflies is present in the

271 diversity of wing morphs exhibited by European species. Males of Calopteryx exul (Selys),

272 inhabiting north Africa, have no pigmentation on their wings and so resemble females.

273 Calopteryx virgo virgo has no pigmentation at the base or the tip of the wing and resembles

274 Calopteryx splendens found in eastern Europe. Calopteryx splendens balcanica females have

275 pigmented wings which resemble the male (androchrome). Wing pigmentation polymorphism is

276 also present in males of the calopterygid damselfly Mnais costalis (Selys), where clear-winged

277 males exhibit a "sneaker" mating strategy while orange-winged males are territorial (Plaistow \&

278 Tsubaki 2000). Therefore, there is evidence from the Calopterygidae for male-mimicking 
279 females, female-mimicking males and, possibly, heterospecific mimicry. Establishing which, if 280 any, of these explanations best fit the $C$. maculata/C. aequabilis system would require further experiments along the same lines as those conducted previously (Tynkkynen et al. 2004; Waage 1979).

283

A conclusive demonstration of convergent character displacement requires knowledge of both the selection pressures and the evolutionary processes that are causing the convergence of traits. Clearly a case for convergent displacement cannot be made purely on the basis of the observations described here, although the patterns resemble those that would be expected from such a process. Very few examples of convergent character displacement have been documented,

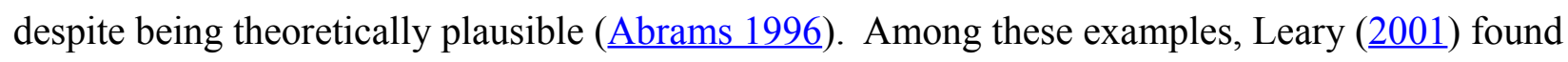
that the nature of the calls given by male toads (Bufo $\mathrm{sp}$ ) to prevent prolonged amplexus by conspecific and heterospecific males converged when in sympatry. This convergence may facilitate interspecific communication to reduce wasteful energy expenditure and exposure to predation. Following the invasion of American mink (Mustela vison (Schreber)) to Belarus, the larger invading species decreased in size while the native European mink (M. lutreola $(\mathrm{L}))$ increased in size (Sidorovich et al. 1999). On the other hand, many examples of divergent character displacement have been documented (Dayan \& Simberloff 2005).

The importance of thermoregulatory behaviour has been noted in a number of Odonata (for a review see Hassall \& Thompson 2008), and a number of adaptations are present. There has been a suggestion that variations in body pigmentation with latitude in Orthetrum cancellatum (L) contribute to enhanced absorption of solar energy ( form of Sympetrum striolatum (Charpentier) found only at the northern range margin where such pigmentation could assist in thermoregulation was previously described as a separate species, Sympetrum nigrescens, before molecular studies demonstrated that the two were synonymous (Pilgrim \& Von Dohlen 2007). The only other study of range-wide variation in wing pigmentation in a damselfly (Calopteryx splendens) also demonstrated no consistent patterns with latitude (Sadeghi et al. 2009), and this has been attributed to different wing morphs being genetically distinct gene pools with intermediates resulting from hybridisation (Sadeghi et al. 2010). This study similarly shows no unequivocal evidence of a latitudinal cline, despite the wide climatic range over which the species occurs. However, the increased pigmentation at 
higher latitudes within the sympatric zone is consistent with a potential role in thermoregulation within this region.

It has been demonstrated that the extent of pigmentation in male wings is an honest indicator of immune function in a number of calopterygid damselflies (Hetaerina americana, ContrerasGarduño et al. 2006; Calopteryx splendens, Rantala et al. 2000; Calopteryx splendens xanthostoma, Siva-Jothy 2000). As such, variation in pigmentation may be under indirect selective pressures acting on immune function. Parasites increase in diversity and abundance closer to the equator (Poulin \& Morand 2000) and there is some evidence that virulence follows a similar pattern (Møller et al. 2009). This selection may result in greater immune function at lower latitudes (e.g. Ardia 2007). Thus we may expect to observe greater pigmentation at lower latitudes where immune challenge is at its highest. However, damselflies emerging later in the season exhibit greater immune responses (Yourth et al. 2002) which are associated with higher temperatures (Robb \& Forbes 2005). The melanotic encapsulation involved in the immune response follows the same biochemical pathways as those involved in melanisation of the cuticle (Marmaras et al. 1996). Thus, a negative correlation between pigmentation and latitude (or a positive correlation with temperature) is predicted by both parasite-mediated selection and plastic responses to temperature, but there is no evidence of this pattern in the present study.

The results presented here fill a gap in the knowledge of geographical patterns of wing pigmentation in a well-studied two-species system. In so doing, two key results present themselves. First, there is geographical pattern in wing pigmentation that would suggest variation in thermoregulatory potential across the range. Second, there is strong evidence for variation in wing pigmentation in male $C$. maculata in relation to its co-occurrence with a congener, $C$. aequabilis. This pattern of variation is qualitatively similar to patterns seen in $C$. maculata females, C. aequabilis females, and C. aequabilis males. This apparent convergence of a character that is important in species identification may contribute to the divergent character displacement observed in species recognition behaviour in the same system (Waage 1975).

\section{ACKNOWLEDGEMENTS}

I would like to thank Arne Iserbyt, Mary Burnham, Chris Lewis, Shari Sokay, Darrin O'Brien, Fred Sibley, Giff Beaton, George Harp, George Sims, Harris Luckham, Mike Luckham, John Abbott, Joseph Carson, Jeni Eggers and Eliott Porter, Jeffrey Willers, Michael Blust, Marion 
Dobbs, Mark Musselman, Pat Heithaus, Rick Abad, Ryan Spafford, Steve Hummel, Sarah Richer, Timothy Sesterhenn, William Lamp and Wade Worthen for giving so graciously of their time to assist with collections. Carley Centen provided valuable assistance in the field. Tom Langen provided assistance with logistics. Jonathan Waage, Jason Pither and several anonymous referees provided extremely helpful comments on an earlier draft of the manuscript.

\section{REFERENCES}

Abbott JC. 2007. OdonataCentral: An online resource for the distribution and identification of Odonata. . available at http://www.odonatacentral.org. (Accessed: April 01, 2010): Texas Natural Science Center, The University of Texas at Austin.

Abrams PA. 1996. Evolution and the consequences of species introductions and deletions. Ecology 77:1321-1328.

Ardia DR. 2007. The ability to mount multiple immune responses simultaneously varies across the range of the tree swallow. Ecography 30:23-30.

Badyaev AV, and Young RL. 2004. Complexity and integration in sexual ornamentation: an example with carotenoid and melanin plumage pigmentation. Journal of Evolutionary Biology 17:1317-1327.

Contreras-Garduño J, Canales-Lazcano J, and Córdoba-Aguilar A. 2006. Wing pigmentation, immune ability, fat reserves and territorial status in males of the rubyspot damselfly, Hetaerina americana. Journal of Ethology 24:165-173.

Dayan T, and Simberloff D. 2005. Ecological and community-wide character displacement: the next generation. Ecology Letters 8:875-894.

Dijkstra K-DB, and Lewington R. 2006. Field Guide to the Dragonflies of Britain and Europe. Gillingham, UK: British Wildlife Publishing.

Diniz-Filho JAF, Bini LM, and Hawkins BA. 2003. Spatial autocorrelation and red herrings in geographical ecology. Global Ecology and Biogeography 12:53-64.

ESRI. 2006. ArcGIS v.9.2. Redlands: Environmental Systems Research Institute, Inc.

Fedorov S. 2008. GetData Graph Digitizer v2.24: http://getdata-graph-digitizer.com/.

Grant PR. 1972. Convergent and divergent character displacement. Biological Journal of the Linnean Society 4:39-68.

Grether GF, Losin N, Anderson CN, and Okamoto K. 2009. The role of interspecific interference competition in character displacement and the evolution of competitor recognition. Biological Reviews 84:617-635. 
371 Hassall C. 2013. Time stress and temperature explain continental variation in damselfly body

372 size. Ecography 36:894-903.

373 Hassall C, and Thompson DJ. 2008. The impacts of environmental warming on Odonata: a

374 review. International Journal of Odonatology 11:131-153.

375 Haylock MR, Hofstra N, Klein Tank AMG, Klok EJ, Jones PD, and New M. 2008. A European

376 daily high-resolution gridded dataset of surface temperature and precipitation. Journal of

377 Geophysical Research Series D, Atmospheres 113.

378 Hilfert-Rüppell D. 1998. Temperature dependence of flight activity of Odonata by ponds.

379 Odonatologica 27:45-59.

380 Honkavaara J, Dunn DW, Ilvonen S, and Suhonen J. 2011. Sympatric shift in a male sexual

381 ornament in the damselfly Calopteryx splendens. Journal of Evolutionary Biology 24:139-145.

382 Hooper RE, Tsubaki Y, and Siva-Jothy MT. 1999. Expression of a costly, plastic secondary sexual

383 trait is correlated with age and condition in a damselfly with two male morphs. Physiological

384 Entomology 24:364-369.

385 Johnson C. 1973. Variability, distribution and taxonomy of Calopteryx dimidiata. Florida

386 Entomologist 56:207-222.

387 Kingsolver JG, and Koehl MAR. 1985. Aerodynamics, thermoregulation, and the evolution of

388 insect wings: differential scaling and evolutionary change. Evolution 39:488-504.

389 Kirkton SD, and Schultz TD. 2001. Age-specific behavior and habitat selection of adult male

390 damselflies, Calopteryx maculata. Journal of Insect Behavior 14:545-556.

391 Leary CJ. 2001. Evidence of convergent character displacement in release vocalizations of Bufo

392 fowleri and Bufo terrestris (Anura; Bufonidae). Animal Behaviour 61:431-438.

393 Marmaras VJ, Charalambidis ND, and Zervas CG. 1996. Immune response in insects: The role of

394 phenoloxidase in defense reactions in relation to melanization and sclerotization. Archives of

395 Insect Biochemistry and Physiology 31:119-133.

396 McGraw KJ, and Hill GE. 2000. Differential effects of endoparasitism on the expression of

397 carotenoid- and melanin-based ornamental coloration. Proceedings of the Royal Society: Series B

398 (Biological Sciences) 267:1525-1531.

399 Møller AP, Arriero E, Lobato E, and Merino S. 2009. A meta-analysis of parasite virulence in

400 nestling birds. Biological Reviews 84:567-588.

401 Mullen SP, and Andrés JA. 2007. Rapid evolution of sexual signals in sympatric Calopteryx

402 damselflies: reinforcement or 'noisy-neighbour' ecological character displacement? Journal of

403 Evolutionary Biology 20:1637-1648. 
404 Outomuro D, and Ocharan FJ. 2011. Wing pigmentation in Calopteryx damselflies: a role in 405 thermoregulation? Biological Journal of the Linnean Society 103:36-44.

406 Pilgrim EM, and Von Dohlen CD. 2007. Molecular and morphological study of species-level 407 questions within the dragonfly genus Sympetrum (Odonata: Libellulidae). Annals of the 408 Entomological Society of America 100:688-702.

409 Plaistow SJ, and Tsubaki Y. 2000. A selective trade-off for territoriality and non-territoriality in 410 the polymorphic damselfly Mnais costalis. Proceedings of the Royal Society: Series B 411 (Biological Sciences) 22:969-975.

412 Poulin R, and Morand S. 2000. The diversity of parasites. The Quarterly Review of Biology $413 \quad 75: 277-293$.

414 R Development Core Team. 2013. R: A language and environment for statistical computing. 415 Vienna, Austria: R Foundation for Statistical Computing.

416 Rangel TFLVB, Diniz-Filho JAF, and Bini LM. 2010. SAM: a comprehensive application for 417 Spatial Analysis in Macroecology. Ecography 33:46-50.

418 Rantala MJ, Koskimaki J, Taskinen J, Tynkkynen K, and Suhonen J. 2000. Immunocompetence, 419 developmental stability and wingspot size in the damselfly Calopteryx splendens L. Proceedings 420 of the Royal Society: Series B (Biological Sciences) 267:2453-2457.

421 Rasband WS. (1997-2007) ImageJ. < $\underline{\text { http://rsb.info.nih.gov/ij/>. }}$

422 Robb T, and Forbes MR. 2005. On understanding seasonal increases in damselfly defence and 423 resistance against ectoparasitic mites. Ecological Entomology 30:334-341.

424 Sadeghi S, Adriaens D, and Dumont HJ. 2009. Geometric morphometric analysis of wing shape 425 variation in ten European populations of Calopteryx splendens (Harris, 1782) (Zygoptera: 426 Odonata). Odonatologica 38:343-360.

427 Sadeghi S, Kyndt T, and Dumont HJ. 2010. Genetic diversity, population structure and taxonomy 428 of Calopteryx splendens (Odonata: Calopterygidae): An AFLP analysis. European Journal of 429 Entomology 107:137-146.

430 Sidorovich V, Kruuk H, and Macdonald DW. 1999. Body size, and interactions between 431 European and American mink (Mustela lutreola and M. vison) in Eastern Europe. Journal of 432 Zoology 248:521-527.

433 Siva-Jothy MT. 1999. Male wing pigmentation may affect reproductive success via female choice 434 in a calopterygid damselfly (Zygoptera). Behaviour 136:1365-1377. 
435 Siva-Jothy MT. 2000. A mechanistic link between parasite resistance and expression of a sexually 436 selected trait in a damselfly. Proceedings of the Royal Society: Series B (Biological Sciences) $437 \quad 267: 2523-2527$.

438 Siva-Jothy MT, Gibbons DW, and Pain D. 1995. Female oviposition site preference and egg 439 hatching success in the damselfly Calopteryx splendens xanthostoma. Behavioral Ecology and 440 Sociobiology 37:39-44.

441 Sternberg K. 1996. Colours, colour change, colour patterns and "cuticular windows" at light traps 442 - their thermoregulatory and ecological significance in some Aeshna species. Zoologischer 443 Anzeiger 235:77-88.

444 Sternberg K. 1997. Adaptation of Aeshna caerulea (Strom) to the severe climate of its 445 environment (Anisoptera: Aeshnidae). Odonatologica 26:439-449.

446 Stettmer C. 1996. Colonisation and dispersal patterns of banded (Calopteryx splendens) and 447 beautiful demoiselles (C. virgo) (Odonata: Calopterygidae) in south-east German streams. 448 European Journal of Entomology 93:579-593.

449 Stoehr AM. 2006. Costly melanin ornaments: the importance of taxon? Functional Ecology $450 \quad 20: 276-281$.

451 Svensson EI, and Friberg M. 2007. Selective predation on wing morphology in sympatric 452 damselflies. The American Naturalist 170:101-112.

453 Svensson EI, Karlsson K, Friberg M, and Eroukhmanoff F. 2007. Gender differences in species 454 recognition and the evolution of asymmetric sexual isolation. Current Biology 17:1943-1947.

455 Svensson EI, and Waller JT. 2013. Ecology and Sexual Selection: Evolution of Wing 456 Pigmentation in Calopterygid Damselflies in Relation to Latitude, Sexual Dimorphism, and 457 Speciation. The American Naturalist 182:E174-E195.

458 Talloen W, Van Dyck H, and Lens L. 2004. The cost of melanization: butterfly wing coloration 459 under environmental stress. Evolution 58:360-366.

460 Tsubaki Y, Samejima Y, and Siva-Jothy M. 2010. Damselfly females prefer hot males: higher 461 courtship success in males in sunspots. Behavioral Ecology and Sociobiology 64:1547-1554. 462 Tynkkynen K, Grapputo A, Kotiaho JS, Rantala MJ, Väänänen S, and Suhonen J. 2008. 463 Hybridization in Calopteryx damselflies: the role of males. Animal Behaviour 75:1431-1439. 464 Tynkkynen K, Rantala MJ, and Suhonen J. 2004. Interspecific aggression and character 465 displacement in the damselfly Calopteryx splendens. Journal of Evolutionary Biology 17:759466767. 
467 Van Gossum H, Stoks R, and De Bruyn L. 2001. Frequency-dependent male mate harassment and 468 intra-specific variation in its avoidance by females of the damselfly Ischnura elegans. Behavioral 469 Ecology and Sociobiology 51:69-75.

470 Waage JK. 1973. Reproductive behavior and its relation to territoriality in Calopteryx maculata

471 (Beauvois) (Odonata: Calopterygidae). Behaviour 47:240-256.

472 Waage JK. 1975. Reproductive isolation and the potential for character displacement in the 473 damselflies, Calopteryx maculata and C. aequabilis (Odonata: Calopterygidae). Systematic 474 Zoology 24:24-36.

475 Waage JK. 1979. Reproductive character displacement in Calopteryx (Odonata, Calopterygidae). 476 Evolution 33:104-116.

477 Watt WB. 1968. Adaptive significance of pigment polymorphisms in Colias butterflies. I. 478 variation of melanin pigment in relation to thermoregulation. Evolution 22:437-458.

479 Yourth CP, Forbes MR, and Smith BP. 2002. Immune expression in a damselfly is related to time 480 of season, not to fluctuating asymmetry or host size. Ecological Entomology 27:123-128. 


\section{Table 1 (on next page)}

General linear models describing variation in wing pigmentation in Calopteryx maculata.

Table 1 - Parameter estimates from general linear models (weighted by square root of sample size) describing variation in wing pigmentation in Calopteryx maculata males. DF=1 for all parameters. 


\begin{tabular}{lrrrrrrrr} 
& \multicolumn{3}{c}{ Fore wing pigmentation } & & & \multicolumn{3}{c}{ Hind wing pigmentation } \\
& Parameter & $\mathrm{t}$ & $\mathrm{p}$ & & Parameter & $\mathrm{t}$ & $\mathrm{p}$ \\
${$\cline { 2 - 4 }$} }$ & -0.0017 & -0.298 & 0.768 & & -0.0015 & -0.367 & 0.717 \\
Latitude & -0.3068 & -0.994 & 0.329 & & -0.0944 & -0.428 & 0.672 \\
Sympatry & $\mathbf{2 . 8 4 3 8}$ & $\mathbf{5 . 0 9 7}$ & $<\mathbf{0 . 0 0 1}$ & & $\mathbf{2 . 2 5 9 0}$ & $\mathbf{5 . 5 9 1}$ & $<\mathbf{0 . 0 0 1}$ \\
Latitude*sympatry & -0.5589 & -1.574 & 0.126 & & $\mathbf{- 0 . 5 2 8 0}$ & $\mathbf{- 2 . 0 6 7}$ & $\mathbf{0 . 0 4 8}$ \\
& & & & & & & & 0.581 \\
$\mathrm{R}_{\text {adj }}^{2}$ & & & 0.547 & & & & \\
\hline
\end{tabular}




\section{Figure 1}

Map of sites with transparency of wings

Figure 1 - Geographical distribution of Calopteryx maculata (light grey) and Calopteryx aequabilis (hashed region). Points mark the location of sampling sites for $C$. maculata and the size of the point is proportional to the grayscale value of the wing pigmentation intensity (larger symbol = lighter wings) for areas of sympatry (filled symbols) and allopatry (open symbols). See Figure 3 for illustrations of wing pigmentation variation.

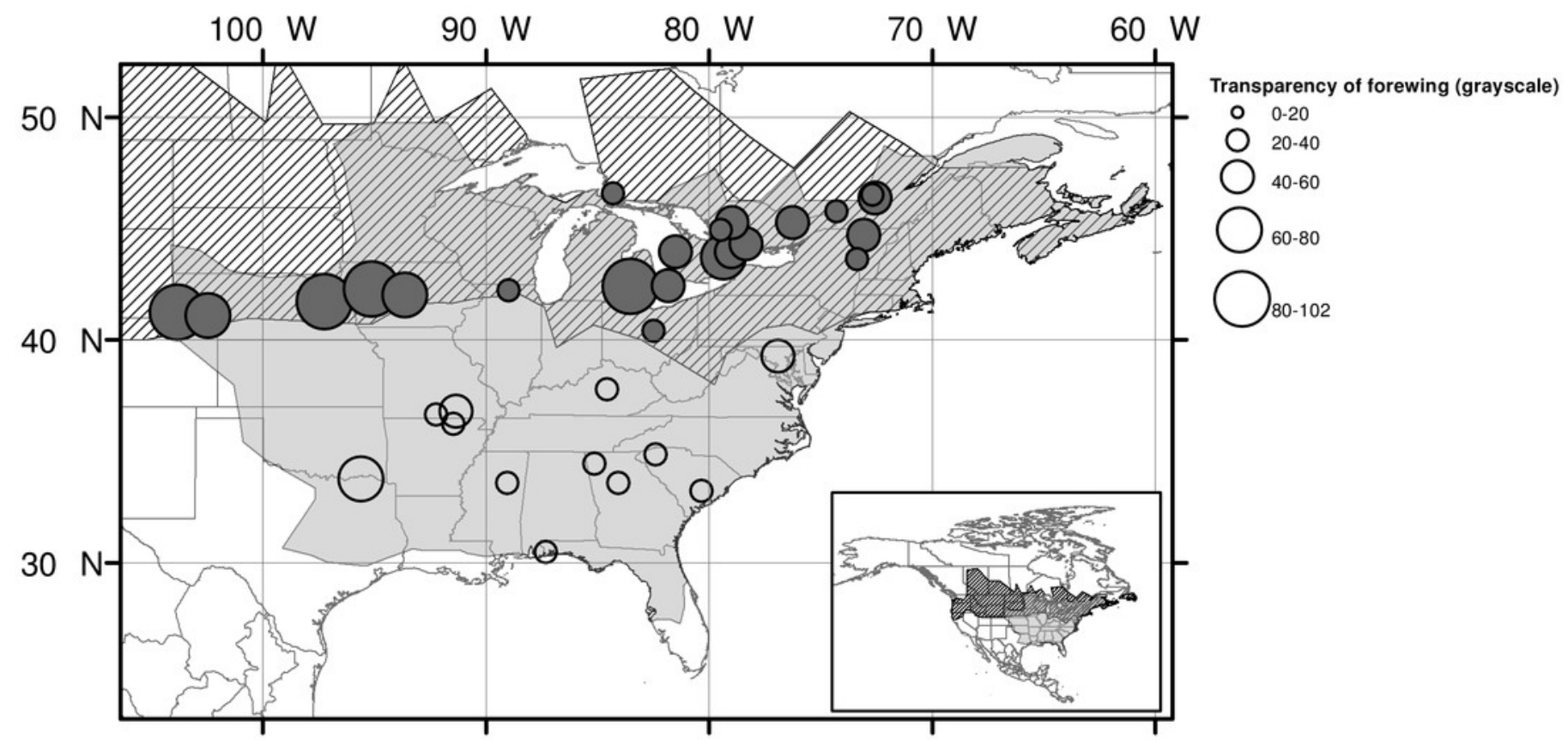




\section{Figure 2}

Variation in wing pigmentation in Calopteryx maculata

Figure 2 - Latitudinal patterns of pigmentation in C. maculata males where populations are allopatric (open circles) and sympatric (closed circles) with $C$. aequabilis. Error bars are 1SE. The $y$-axis is arranged to show increasing levels of pigment from bottom to top, but note that the measurement was grayscale where higher values correspond to lighter colours. Displayed on the right are examples of wings with pigmentation intensities corresponding to their locations on the $y$-axis. See Table S1 for sample sizes and means, and Table S2 for raw data.

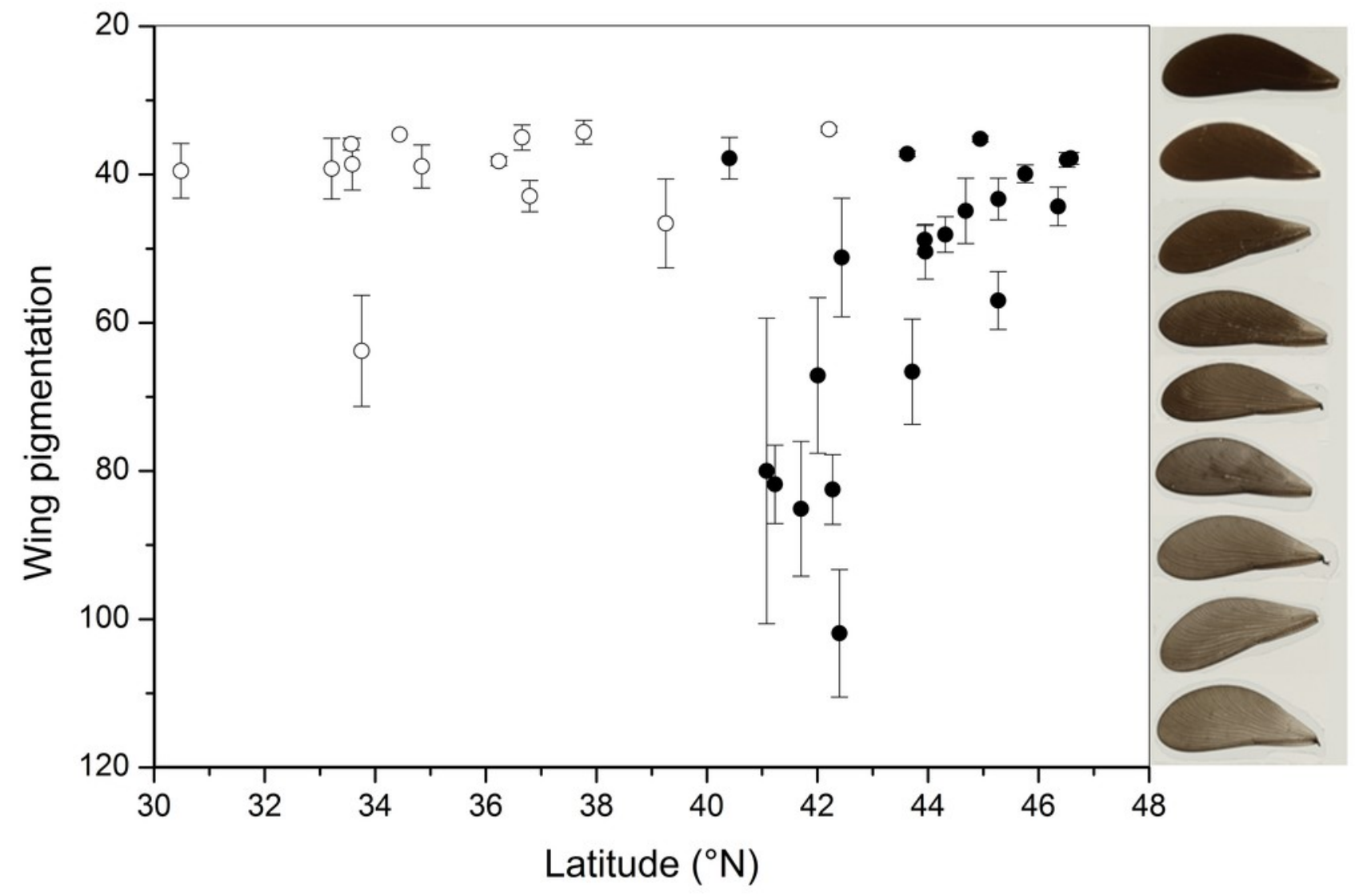




\section{Figure 3}

Comparison of wing pigmentation variation between Calopteryx maculata and $C$. aequabilis

Figure 3 - Comparison of variation wing pigmentation between (A) C. maculata males (from the present study), (B) C. aequabilis females (from Waage, 1979), (C) C. maculata males (from Waage, 1979), and (D) C. maculata females (from Waage, 1979). All y-axes represent qualitatively the same trait: pigmentation of the wing, with low values (top of $y$-axes) corresponding to darker wings and higher values (bottom of $y$-axes) to greater transparency. However, the measures vary in the way in which they were collected: for $C$. aequabilis males it is the proportion of the wing length that is unpigmented, for $C$. aequabilis and $C$. maculata females it is the transparency of the dark area of the wing (using a densitometer), and for $C$. maculata males it is the mean grayscale value of a wing scan (see methods above). All error bars are standard errors. Note in all cases that pigmentation is highest at the southern margin of the zone of sympatry with subsequent declines further north. $t$ 


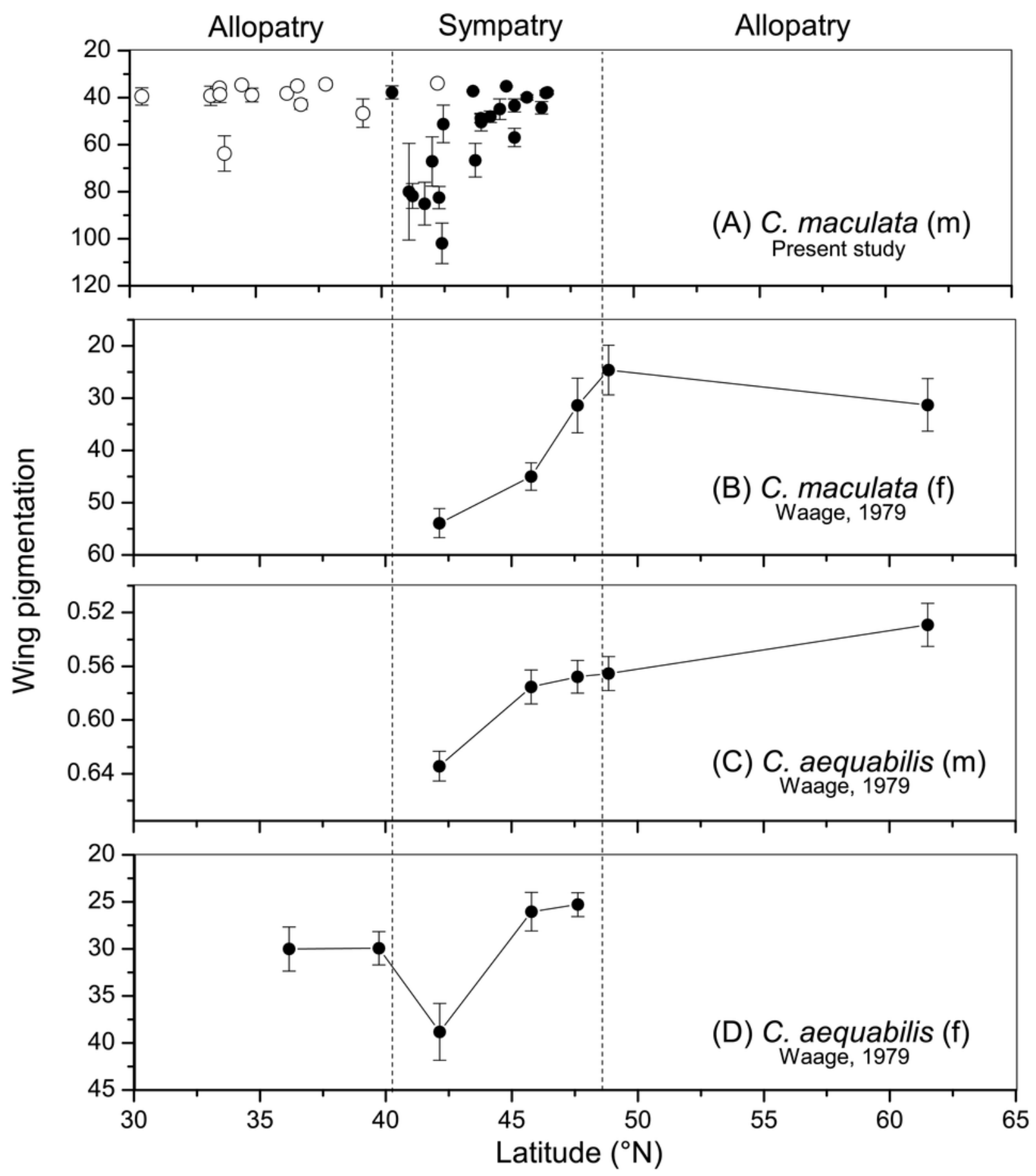

